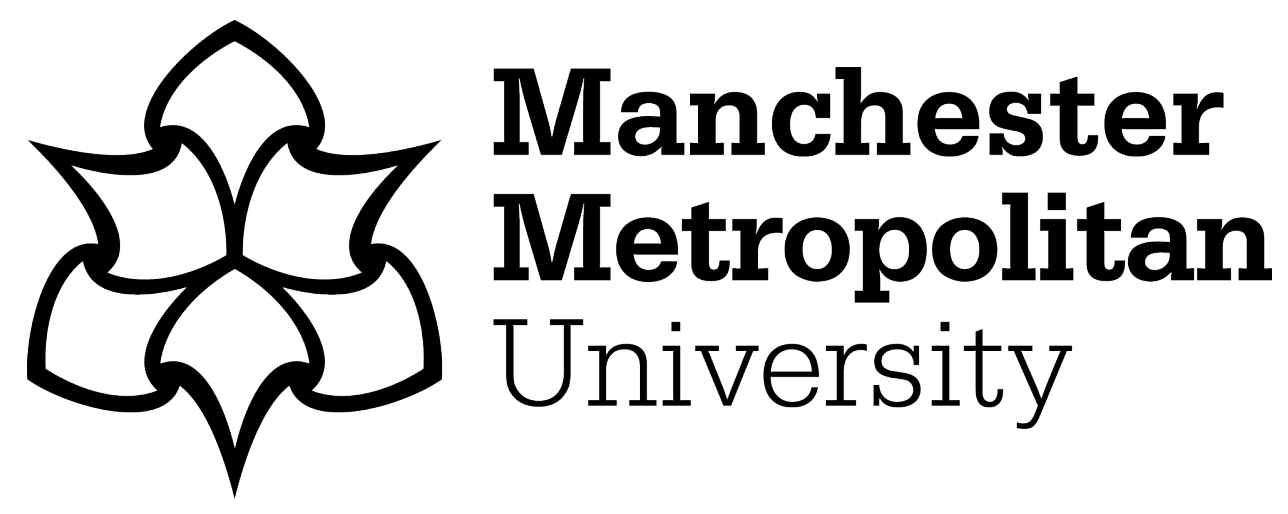

Persson, S, Dhingra, K and Grogan, S (2018) Attributions of victim blame in stranger and acquaintance rape: a quantitative study. Journal of Clinical Nursing, 27 (13-14). pp. 2640-2649. ISSN 0962-1067

Downloaded from: https://e-space.mmu.ac.uk/620036/

Version: Accepted Version

Publisher: Wiley

DOI: https://doi.org/10.1111/jocn.14351

Please cite the published version 


\title{
Attributions of Victim Blame in Stranger and Acquaintance Rape: A Quantitative
}

\section{Study}

\begin{abstract}
Aims and objectives: are to, on a sample of nurses and the general public, examine whether victim blame varies according to level of familiarly between victim and perpetrator. It also examines how Ambivalent Sexism (AS) and Rape Myth Acceptance (RMA) impacts on this. Background: Around one in five women will be victims of sexual assault during their lifetime. The majority are acquaintance rapes, and these victims are generally attributed more blame than victims of stranger rape. Research indicates that nurses hold similar attitudes on gender roles and victim blame as do the general public.
\end{abstract}

Methods: Eighty-one participants read a story depicting a sexual assault of a woman by either a stranger or an acquaintance, and completed scales measuring victim blame, AS and RMA.

Results: indicated that victim-perpetrator relationship, benevolent sexism (BS), hostile sexism (HS) and whether he participant was a nurse contributed to the variance in attributed victim blame. Hierarchical regressions revealed that whether or not the participant was a nurse contributed to the variance in victim blame in the acquaintance rape condition, and HS and BS contributed to the variance in victim blame in the stranger rape condition.

Conclusions: This paper gives a novel insight into attitudes involved in victim blame in rape cases, and makes a unique comparison between nurses and the general public. Findings suggests that victim blame correlates primarily with aggressively sexist attitudes, and that nurses generally attribute more blame to the victim of acquaintance rape. 


\section{ATTRIBUTIONS OF VICTIM BLAME}

Relevance to clinical practice: This study has practical implications for the provision of medical services for victims of sexual assault, as it highlights problems in identifying and accessing rape victims, as well as recommending the sexual assault training of all practicing nurses.

\section{What does this paper contribute to the wider global clinical community?}

- Drawing on international research, this paper highlights key issues involved in encouraging victim of rape (specifically acquaintance rape) to access medical services following their assault.

- By making a novel comparison between a medical and non-medical sample, this paper examines key attitudinal factors that are likely to impact the care given to of victims of sexual assault by medical nurses.

- By examining both of the above, this paper gives recommendations for the clinical practice of nurses, which will be relevant in a global community.

Keywords: Acquaintance Rape; Ambivalent Sexism; Rape Myth Acceptance; Nurses; Victim Blame 


\section{Attributions of Victim Blame in Stranger and Acquaintance Rape: A Quantitative}

\section{Study}

It is estimated that one in five UK women, and one in six US women will be victims of sexual assault during their lifetime (Rape Crisis UK, 2016; Rape Abuse \& Incest National Network (RAINN), 2016). It is suggested only between $16.5-26.1 \%$ of these assaults are reported, which would make rape one of the crimes with the highest levels of under-reporting (RAINN, 2016; Lisak \& Miller, 2002). The conceptualisation of attributions in rape cases is sometimes referred to as the 'rape perception framework', and within this falls situational factors such as relationship between victim and perpetrator (Grubb \& Harrower, 2008). Most research normally distinguishes between stranger rape and acquaintance rape, where the former refers to a sexual assault perpetrated by someone the victim has never encountered before. The definition of acquaintance rape is significantly broader, including perpetrators ranging from someone the victim has just met, to a partner or a spouse (Rape Crisis UK, 2016). Studies from both the UK and the US confirm that acquaintance rape is more common than stranger rape, the most prevalent perpetrator being a current partner (Rape Crisis UK, 2016; RAINN, 2016). The estimated prevalence tends to differ with the sampling method; lower estimates are found among studies relying on victims reporting the offence to the police or medical services, and higher in general community samples (Logan et al., 2007; Koss et al., 1988). This suggests that victims of acquaintance rape do not seek the specialist medical care they are likely to need, highlighting the importance to encourage medical practitioners to identify possible victims in more generalised care.

It generally appears that victims of rape are under more scrutiny than victims of other

offences. For instance, Bieneck and Krahé (2010) found that participants were more likely to blame a female victim of rape than a female victim of robbery, especially when the victim knew the perpetrator. Referring to this as a leniency bias, the authors argue that there is 


\section{ATTRIBUTIONS OF VICTIM BLAME}

already a disproportionally large attribution of blame on victims of sexual assault, and that this is amplified when the perpetrator is an acquaintance. Numerous studies have found that people are more likely to blame victims of acquaintance rape than stranger rape (Abrams et al., 2003; Viki et al., 2004). Conversely, participants tend to attribute less blame to perpetrators of acquaintance rape than perpetrators of stranger rape (Viki et al., 2004; Frese et al., 2004). The closer the relationship, the less blame is attributed to the perpetrator and the more to the victim (Bieneck \& Krahé, 2010). There are several explanations for why this might be, including attitudes relating to Ambivalent Sexism and Rape Myth Acceptance.

\section{Ambivalent Sexism}

Conceptualised by Glick and Fiske in 1996, Ambivalent Sexism (AS) refers to the sometimes differential and ambivalent nature of sexist attitudes towards women. The researchers argue that there are two types of sexism: Benevolent and Hostile Sexism that form an ambivalently sexist attitude towards women, where women in traditionally feminine roles (i.e. mothers or housewives) are held in high regard, whilst non-traditional women (e.g. those who are sexually promiscuous) are perceived in highly negative terms. Benevolent Sexism (BS) is concerned with differentiating women from men in highly stereotypical terms, stressing the inherent femininity of women, and thus implicitly, the masculinity of

men. It generally focuses on women's supposed moral superiority (particularly in sexual relationships, thus resulting in greater perceived culpability when this superiority is regarded as having been compromised), pureness, and fragility, which in turn results in it being the responsibility of men to offer women protection. Conversely, Hostile Sexism (HS) is the commonly recognised type of sexism that encompasses negative views of women, where women are perceived less intelligent and deceitful. They are separate, but complementary, concepts and have been found to positively correlate with each other at levels between .4 and .5 (Glick \& Fiske, 2011). 


\section{ATTRIBUTIONS OF VICTIM BLAME}

There is a complex relationship between AS and victim and perpetrator blame. Abrams et al. (2003) found that among a university sample, higher levels of BS correlated with higher levels of attributed victim blame in acquaintance rape scenarios; there was no significant difference in the stranger rape condition. This might be because people who believe in traditional gender roles regard women as, due to their supposed moral superiority and pureness, guardians of sexuality, and thus reinforce the notion that victims of acquaintance rape have violated gender rules, and were complicit in the assault. This is supported by findings that participants high in BS attribute more blame to a victim of acquaintance rape if she was assaulted during an act of infidelity, as compared to a victim whose marital status was unknown (Viki \& Abrams, 2002). Moreover, Viki et al. (2004) found that BS had a negative correlation with attributed perpetrator blame and recommended sentence length in acquaintance rape scenarios, but not in stranger rape scenarios. Finally, Masser et al. (2010) found a positive relationship between victim blame and HS. For the current study, is therefore expected that there will be a relationship between HS, BS and victim blame in the acquaintance rape scenario, but not in the stranger rape scenario.

\section{Rape Myth Acceptance}

Rape Myth Acceptance (RMA) is defined as the tendency to trivialize and minimize the impact and prevalence of sexual assault (Bohner et al., 1998). Bohner et al. (2009) outline four types of rape myths: victim blaming, disbelief in claims of rape, exoneration of the perpetrator and the belief that only certain women are raped. They all encompass stereotypical views on men and women, and what constitutes sexual relationships. The concept of RMA has its roots in feminist theory, where rape is seen as a means by which men exert power over women. Researchers argue that RMA is pervasive and widely held in all levels of society (Sleath \&Woodhams, 2014; Bohner et al., 2009. It correlates with Hostile and Benevolent Sexism (Grubb \& Turner, 2012). Importantly, high levels of RMA are 
associated with high levels of victim blame (Grubb \& Turner, 2012; Bohner et al., 2009). The relationship between victim blame and RMA appears to be stronger in acquaintance rape scenarios (Krahé et al., 2007). For instance, a study by Frese et al. (2004) found that RMA had the strongest influence on attributions of victim blame in ambiguous rape scenarios, i.e. when the victim knew the perpetrator prior to the attack. This might be because people rely on mental short-cuts (often stereotypical in nature) to make judgments when lacking situational cues, which is often the case in rape cases (Bohner et al., 2009). It might also be that certain aspects of the victim's behaviour reinforce and activate schemas linked to gender roles and sexual aggression (Grubb \& Turner, 2012). For the current study, it is therefore expected that high levels of RMA will predict higher levels of victim blame, and that this relationship will be stronger in the acquaintance rape scenario.

\section{Medical Treatment of Rape Victims}

More than half of rape victims choose not to seek medical treatment for their injuries, and this estimation is likely only the tip of the iceberg (Centers for Disease Control and Prevention (CDC), 2012; Tjaden \& Thoennes, 2006). Regarding victims of acquaintance rape, Feldhaus et al. (2000) report that among a sample of 360 U.S. women, only $29 \%$ of victims assaulted by someone they knew sought medical treatment for their injuries, as compared to $70 \%$ of victims assaulted by a stranger. As not all rape victims seek the medical care they might need, particularly if assaulted by someone they know, it makes the case for encouraging nurses to identify these types of victims when seeking care for other issues that could be related to, but not necessarily specified as a result of, sexual assault. For those that do seek specialist care following a rape, nurses might in some cases be the first point of contact for a victim (Campbell et al., 2012; Möller et al., 2013). Research from the UK indicates that rape cases where victims are examined by a nurse who have been trained in the SANE program (a sexual assault training model focusing on psychological and medical care) 


\section{ATTRIBUTIONS OF VICTIM BLAME}

have a higher chance of reaching successful prosecution (Campbell et al., 2012). Previous research has indicated that nurses and nursing students hold similar beliefs about rape victims as do the general public, such as attributing more blame to the woman if she is assaulted by someone she knew or if she was perceived to be carless at the time of the assault (Alexander, 1980; Grubb \& Harrower, 2008). Uji et al. (2007) found that Japanese nurses, as compared to social workers and psychologists, held the highest levels of RMA. In a qualitative study on forensic care for rape victims, McMillan and White (2015) found that English forensic nurses were prone to blaming the victim and exonerating the perpetrator, particularly in cases that did not fit the stereotypical perception of a rape. This is line with previous research on nonmedical populations suggesting higher levels of believed precipitation for female victims of acquaintance and partner rape as compared to stranger rape (Cowan, 2000). There is an evident need for further quantitative research that investigates attitudes relating to rape and victim blame among nurses.

\section{The Current Study}

The current study aims to quantitatively investigate the differential nature of blame attributions in stranger and acquaintance rape in medical and non-medical populations, by modelling Abrams and colleagues' (2003) study. Participants are randomly allocated to read one of two short vignettes depicting a sexual assault of a woman, where the perpetrator is either a stranger or an acquaintance (independent variable) and answer questions about victim blame (dependent variable). The second independent variable is whether or not the participant is a nurse. Further variables of interest include scores on the Ambivalent Sexism Inventory (ASI) and the Acceptance of Modern Myths About Sexual Aggression scale (AMMSA). Participants also answer demographical questions on age and gender, and consist of two groups: nursing staff and students, as well as a convenience sample from the general public. By combining the above variables, this study contributes to, and expands, the existing 


\section{ATTRIBUTIONS OF VICTIM BLAME}

literature, as well as making novel comparison between the general public and nursing staff and students.

Thus, the objectives are as follows:

- To analyse whether attributed victim blame varies according to victim-perpetrator relationship

- To examine the relationship between victim-perpetrator relationship, victim blame, Benevolent Sexism, Hostile Sexism and Rape Myth Acceptance

- To examine whether there are differences in responses between nurses and nonnurses.

\section{Method}

\section{Design}

The current study employed a quantitative $2 \times 2$ design, where participants were randomly allocated to one of two conditions: to read a short vignette about either a stranger or an acquaintance rape scenario. The second independent variable was whether participants were nurses or members of the general public. Following this, participants' responses to victim and perpetrator blame were recorded. The moderating effects of Ambivalent Sexism and Rape Myth Acceptance were also examined.

\section{Data analysis}

A 2x2 Analysis of Variance (ANOVA) was conducted to explore the interaction between type of rape (two levels; stranger or acquaintance perpetrator) and occupation (two levels; nurse or general public) with victim blame as the dependent variable. A 2x2 ANOVA explores the main effect of each of the two variables (rape condition and occupation) as well as the interaction between the two on the dependent variable. This was followed by a series of t-tests, to explore the effects further. To control for the number of comparisons we employed the Bonferroni correction method. Then, four separate Pearson's correlations (for 
occupational groups and type of rape) were performed to assess the relationship between the continuous variables.

Following this, hierarchical multiple regressions were used to determine the source of variance in victim blame. All variables were entered stepwise into the model, with type of rape expected to be the strongest predictor. Then, two separate hierarchical regressions were conducted: one for each type of rape condition (stranger or acquaintance). Again, all variables were entered step-wise into the model. Analysis was conducted in SPSS 21.

This analytic approach is adopted whilst considering that recent Monte Carlo simulations (Schmider et al., 2010) show that high degrees of skew have little impact on type 1 errors. Also, simulation studies of nonparametric tests (Zimmerman, 2000) suggest that these types of tests do not protect against inferential problems amounting from typical small sample issues, for example, heterogeneity of variances across samples.

\section{Participants}

Participants were nursing staff and students, as well as members of the general public, from England and Sweden, as the primary researcher had access to participants in both countries. The rationale behind including participants from two countries was to increase the scope of the research, and to provide a foundation for clinical practice not limited to a single country by increasing international relevance. As the medical community is increasingly global, and national policies are inspired by those implemented in other countries, the current sample aims to build on this increased pattern of international co-operation. Participants were recruited on university grounds and through online advertising. There were 81 participants in total; 42 nurses and 39 members of the general public. Swedish and English participants were subjected to the same randomisation process to ensure participant homogeneity between conditions. Sample size was based on Clark-Carter's (2003) guidelines on sample sizes large enough to detect a medium effect size. For those participants who stated age $(N=72)$, the 
mean age was 31.9 years $(\min =20$ years, $\max =69$ years $)$. The mean age for nurses was 34.0 years $(\mathrm{SD}=12.04)$ and the mean age for members of the general public was $29.4(\mathrm{SD}=$ 8.29) years. All participants disclosed gender, and $84 \%$ were female and $16 \%$ were male. Two Chi Square tests revealed that there was not a significant gender-difference between the two rape-condition groups, $\chi^{2}(1)=.88, p=.665$, but that there were significantly more female than male nurses, $\chi^{2}(1)=12.10, p=.001$.

\section{Materials}

The vignettes and accompanying victim blame scale were adopted from Abrams et al. (2003), and comprised of a short story depicting a sexual assault by a man, Jason, of a woman, Kathy. The vignettes were largely identical, with the crucial difference being that Jason was either a stranger, or a casual acquaintance Kathy met at a party. After reading the vignette, participants answered 7 items measuring attributed victim and perpetrator blame and indicated their answers on a 7-point scale. A 1 indicated that the participant did not agree at all, and a 7 indicated that they completely agreed. For the question on who was to blame for the assault, a 1 indicated Jason and a 7 indicated Kathy. Example items included, "How much do you think Kathy should blame herself for what happened?" and "How much sympathy do you feel for Kathy?" The items have been found to adequately represent the degree to which participants blame the victim of the assault (Abrams et al., 2003). The scale had a Cronbach's alpha of .844 and .809 for nurses and the general public respectively.

ASI (Ambivalent Sexism Inventory, Glick \& Fiske (1996). The ASI is a 22-item scale measuring Ambivalent Sexism among both men and women (Glick \& Fiske, 1996).

Participants read statements about men and women's role in society, and indicated their agreement on a 6-point Likert type scale. A 0 indicated that the participant strongly disagreed, and a 5 indicated that the participant strongly agreed. The scale measured Hostile 
and Benevolent Sexism on two sub-scales, making it possible to assess the constructs separately, and their relationship with one another. A scale example of Hostile Sexism was "Women are too easily offended" and a scale example of Benevolent Sexism was "Women should be cherished and protected by men". The constructs were measured by three shared content categories: paternalism, gender differentiation and heterosexuality. The ASI has been found to reliably predict AS and used in conjunction with Impression Management scales (Glick \& Fiske, 2011). The scale had a Cronbach's alpha of .879 and .872 for nurses and the general public respectively. The Hostile and Benevolent Sexism sub-scales had a Cronbach's alpha of .862 and .870 , and .827 and .712 respectively.

AMMSA (Acceptance of Modern Myths About Sexual Aggression), Gerger et al. (2013). The AMMSA measures endorsement of Rape Myths among both men and women. The scale consisted of 30 items where participants indicate their agreement to each statement on a 7-point Likert type scale. A 1 indicated that participants completely disagreed, and a 7 indicated the participant agreed completely. This scale was chosen as it, by using subtler wording and less colloquial language, addresses the skew often found in traditional measures of RMA, where participants' desire to answer in a socially acceptable way led responses to cluster in the low end (Bohner et al., 2009). The scale reflected five content categories: denial of the scope of the problem of sexual violence (e.g. "Many women tend to interpret a wellmeant gesture as a sexual assault"), antagonism towards victim demands (e.g. "Although victims of armed robbery have to fear for their life, they receive far less psychological support than do rape victims"), lack of support for policies designed to help alleviate the effects of sexual violence (e.g. "Nowadays, the victims of sexual violence receive sufficient help in the form of women's shelters, therapy offers and support groups"), beliefs that male coercion forms a natural part of sexual relationships (e.g. "When a woman starts a relationship with a man she must be aware that the man will assert his right to have sex") and 


\section{ATTRIBUTIONS OF VICTIM BLAME}

beliefs that exonerate male perpetrators by blaming the victim or the circumstances (e.g. "Alcohol is often the culprit when a man rapes a woman"). The AMMSA has been validated internationally and used in conjunction with Impression Management scales (Bohner et al., 2007). The AMMSA had a Cronbach's alpha of .935 and .938 for nurses and the general public respectively.

BIDR (Balanced Inventory of Desirable Responding), Pauhlus (1991). In line with the Abrams et al. (2003) study, an Impression Management scale was included. BIDR consists of 40 items relating to behaviours most people engage in, but would not normally admit to, such as gossiping or littering. Participants indicated how true each statement was on a 7-point Likert type scale. A 1 indicated that the statement was not true, and a 7 indicated that the statement was very true. Examples included "I am a completely rational person" and, "Once in a while I laugh at a dirty joke". The BIDR had a Cronbach's alpha of .867 for nurses, and .885 for the general public.

\section{Procedure}

Participants were recruited online and through university mailing lists, where they could access an online platform to anonymously complete the questionnaire. Alternatively, participants were approached in a university building and completed the questionnaire using pen and paper.

\section{Ethical Considerations}

The study gained ethical approval from a British University and were conducted in line with BPS guidelines. Participants were made aware that responses would be kept anonymous, and that they were free to withdraw without giving a reason at any time. Data were kept securely and anonymously. Participants were made aware of the content of the study before agreeing to partake. Due to the sensitive nature of the study content, participants 
were provided with contact details for a sexual assault support organization in the debrief sheet.

\section{Results}

\section{Descriptive Statistics}

Descriptive statistics, including means $(M)$ and standard deviations $(S D)$ for all measures are presented in Table 1.

\section{Comparison Between Groups}

To analyse whether there were any significant interactions between the variables, a 2 x 2 Analysis of Variance (ANOVA) was performed on type of rape and occupation with attributed victim blame as the dependent variable. This demonstrated that there was a significant interaction between the type of rape and occupation on attributed victim blame, $F(1,81)=6.03, p=.016$. A series of $t$-tests were performed to explore this interaction further. There was an overall difference between attributed victim blame in the two assault conditions. Specifically, participants attributed more blame to the victim of acquaintance rape $(M=2.59, S D=1.08)$ than the victim of stranger rape $(M=1.76, S D=.887), t(79)=3.82, p$ $<.001$. This was significant even when controlling for multiple comparisons using the Bonferroni correction. Analysing the two occupational groups separately revealed differences between the two groups. The nurse group attributed more blame to the victim of acquaintance rape $(M=2.12, S D=1.16)$ than the victim of stranger rape $(M=1.71, S D=.79)$, although an independent samples t-test revealed the differences were not significant, $t(40)=1.37, p=$ .179. Conversely, the general public group attributed significantly more blame to the victim of stranger rape $(M=3.23, \mathrm{SD}=.478)$ than the victim of acquaintance rape $(M=1.8, S D=$ $.980), t(37)=5.12, p<.001$. This was significant even when correcting for multiple comparisons. Finally, two independent samples t-tests confirmed that attributions of victim 


\section{ATTRIBUTIONS OF VICTIM BLAME}

blame did not vary significantly between men and women in either the stranger or acquaintance rape condition: $t(46)=.875, p=.369, t(31)=.1 .34, p=.192$.

\section{Correlations}

To examine the relationship between the study variables, Pearson's correlations were conducted (Table 2). This analysis was conducted separately for the two victim-perpetrator relationship conditions, and the two occupational groups, resulting in a total of 4 separate correlation analyses. There were considerable differences in the patterns of correlations between the four data sets. Examining the correlations among nurses in the stranger rape condition, victim blame did not correlate significantly with any other variable. This can be contrasted with the acquaintance rape condition, where victim blame has a significant positive correlation with the AMMSA $(r=.606)$ and HS $(r=.538)$. Similarly, the positive correlation between victim blame and the AMMSA is present in the acquaintance condition among the general public $(r=.600)$. There is also a significant correlation between victim blame and HS ( $(r=.806)$, and victim blame and BS in this group $(r=.786)$. The final data set is distinctly different from the others. There are no significant correlations between victim blame and the other variables in the final data set of the general public in the stranger rape condition; weak non-significant negative correlations are observed between these variables. These correlations suggest that HS and RMA are particularly influential variables in situations of acquaintance. Additionally, there appears to be an effect of benevolent sexism in this condition for non-nurses, an effect that is not found in any other group. As expected, Hostile and Benevolent Sexism correlated positively and significantly in all of the four groups, and so did HS and the AMMSA.

\section{Hierarchical Multiple Regressions}

To examine the amount of variance in attributed victim blame that could be accounted for by the different variables, a number of hierarchical multiple regressions were performed 
(Table 3). The first hierarchical regression was conducted with victim blame as the dependent variable, with participants coded for occupational group and victim-assailant relationship condition. Regressions were also conducted separately for the acquaintance and stranger rape conditions.

The first regression was performed on the complete data set, with victim-perpetrator relationship, BS, HS, RMA, occupation and Impression Management entered step-wise into the regression. The dependent variable was attributed victim blame. The overall step-wise model was significant, $F(5,66)=9.71, p<.001$ with victim-assailant relationship, BS, HS and occupation at step 4 significantly contributing to the variance in victim blame, $\left(\mathrm{R}^{2}\right.$ $=.424)$. The four variables accounted for $42.4 \%$ of attributed victim blame, $\mathrm{R}=.651, p<$ .001. Using Cohen's (1988) criteria, this can be described as a large effect size. Victimperpetrator relationship accounted for $11.5 \%$ of the variance in victim blame $(\mathrm{R}=.340, p=$ .004). However, when controlling for BS, HS and occupation, victim-perpetrator relationship only accounted for $9.24 \%$ of the variance. Type of rape and BS accounted for $30 \%$ of victim blame $(\mathrm{R}=.548, p<.001)$. The squared semi-partial correlation for BS indicated that this accounted for an additional $5.57 \%$ when controlling for victim-perpetrator relationship, HS and occupation. Victim-perpetrator relationship, BS and HS in combination accounted for $38.7 \%$ of the variance in victim blame $(\mathrm{R}=.622, p<.001)$. The squared semi-partial correlation for HS indicated that this accounted for an additional $8.7 \%$ of victim blame when controlling for the three other variables. Finally, when controlling for the other variables, occupation accounted for $6.0 \%$ of attributed victim blame. This suggests that although victim-perpetrator relationship was expected to have the most influence on attributed victim blame, HS had the strongest influence on the variance even when controlling for the other variables. RMA and Impression Management did not contribute significantly to the variance in victim blame. The data met the assumptions of independent errors (Durbin-Watson: 2.03). 
Following this, two separate hierarchical regressions were conducted on the data sets of each victim-perpetrator relationship condition. BS, HS, RMA, occupation and Impression Management were entered step-wise into the regression model. The dependent variable was attributed victim blame.

Acquaintance rape. The overall step-wise model for occupation was significant, $F$ $(1,27)=5.54, p=.003$, with the variable significantly contributing to the prediction of victim blame ( $\left.\mathrm{R}^{2}=.241\right)$ Using Cohen's (1988) criteria, this may be described as a medium effect size. None of the other variables contributed significantly to the variance in victim blame. Occupation accounted for $40.2 \%$ of attributed victim blame $(\mathrm{R}=.700, p=.003)$. The data met the assumptions of independent errors (Durbin-Watson: 1.77).

Stranger rape. The overall step-wise model for BS and HS was significant, $F(3,40)$ $=15.94), p<.001$, with both of the variables at step 2 significantly contributing to the prediction of victim blame, $\left(\mathrm{R}^{2}=.738\right)$. Using Cohen's (1988) criteria, this may be described as a large effect size. BS accounted for $47.0 \%$ of victim blame $(\mathrm{R}=.686, p<.001)$. In combination, $\mathrm{BS}$ and HS accounted for $54.5 \%$ of the variance in victim blame $(\mathrm{R}=.738), p$ $<.001$. The squared semi-partial correlation for HS indicated that this accounted for an additional $11.9 \%$ when controlling for BS. The data met the assumptions of independent errors (Durbin-Watson: 2.20).

The victim-perpetrator relationship conditions differed significantly in variables that contributed to the variance in victim blame, suggesting there might be a difference in the processes involved in perceiving acquaintance rape as compared to stranger rape. Participants' occupation had a significant contribution to the variance in the acquaintance rape condition, an effect that was not observed among participants in the stranger rape condition. Conversely, BS and HS contributed significantly to the variance in the stranger rape condition, whereas no such effect was found in the stranger rape condition. 


\section{Discussion}

As expected, participants attributed significantly more blame to the victim of acquaintance rape than the victim of stranger rape, which is in line with previous research (Abrams et al., 2003). The analyses revealed a significant interaction between occupational group and victim-perpetrator relationship. Specifically, nurses attributed more blame to victims of acquaintance rape than victims of stranger rape; whereas, participants among the general public attributed more blame to the victim of stranger rape. A possible explanation for this could be that around a third of rape victims do not tell anyone about their assault, and that victims of acquaintance rape are less likely to seek medical treatment (CDC, 2012; Rape Crisis UK, 2016); nurses could interpret this as acquaintance rape not being particularly prevalent or very severe. Future research would benefit from further exploring this response pattern among nurses and the general public.

Further analyses revealed that in the acquaintance rape condition, participants in both occupational groups who scored highly on RMA and HS also exhibited elevated victim blame levels. This relationship was not found in the stranger rape condition, suggesting that these attitudes only play a significant role in attributing blame in situations where the victim knows the perpetrator. A possible explanation could be that the acquaintance rape situation is perceived as less stereotypical and more ambiguous, resulting in participants relying on heuristics and schemas to make blame attributions: an obvious heuristic would be to automatically assume that a victim who knew her perpetrator would be somehow complicit in her assault, particularly among people who subscribe to traditional beliefs about rape. This supports previous theories suggesting that victim blame is a result of schemas and scripts relating to beliefs about rape (Bohner et al., 2009). There was a significant correlation between victim blame and $\mathrm{BS}$ in the acquaintance rape condition for the general public, which was not present among nurses in either condition. This is in line with previous 


\section{ATTRIBUTIONS OF VICTIM BLAME}

research, where BS has been found to correlate positively with measures of victim blame in situations where the victim knows the perpetrator (Abrams et al., 2003). Some researchers, such as Masser et al. (2010) argue that BS plays a more moderate role in attributions in victim blame, something that might explain why this relationship was not found in both occupational groups.

Generally, these results support previous research among the general public and student populations, where attitudes relating to sexual violence and gender roles influence blame attributions in acquaintance rape scenarios, but not in stranger rape scenarios (Abrams et al., 2003). A key difference between the present results and previous research is the correlation between attributed victim blame and HS. This could possibly be explained by the relationship between HS and RMA, where these scales correlated significantly throughout the data set. These results indicate that it is primarily aggressively sexist attitudes, not nonaggressive ones that influence blame attributions in the acquaintance rape scenario. Some research up to date has found a relationship between HS and victim blame, but mainly between HS and self-reported rape proclivity in acquaintance rape scenarios (Masser et al., 2010).

Regression analyses revealed that victim-perpetrator relationship, BS, HS and occupation contributed significantly to the variance in victim blame. This is in line with previous studies that have found the first two variables to predict victim blame (Abrams et $a l ., 2003)$. HS was the strongest contributor to the variance in victim blame, even when controlling for the other variables, which further supports the assertion that it was participants' aggressive sexism that predicted attributed victim blame. Whether or not the participant was a nurse also contributed significantly to the variance in victim blame. Separate analyses for the victim-perpetrator relationship conditions revealed that in the acquaintance rape condition, the only variable contributing to victim blame was whether the 


\section{ATTRIBUTIONS OF VICTIM BLAME}

participant was a nurse or not. This relates to the previous analyses where nurses attributed more blame to the victim of acquaintance rape than the victim of stranger rape, a difference that was not found among the general public. Finally, in the stranger rape condition, BS and HS in combination accounted for over $50 \%$ of the variance in attributed victim blame. Crucially, whether or not the participant was a nurse did not influence attributed victim blame. This difference in significant variables between the two victim-perpetrator relationship conditions suggests there are differential processes involved in blame attributions depending on whether or not the victim knows the perpetrator. There further appears to be differential influences depending on respondents' profession. RMA did not predict victim blame in any of the analyses. Finally, Impression Management did not significantly account for the variance in victim blame in any of the conditions.

\section{Study Limitations and Future Research}

A possible limitation of the study was that the original (English) versions of the vignettes and scales were administered to English and Swedish participants alike. However, Sweden is ranked as having one of the highest levels of English proficiency in the world (EF EPI, 2014). Another possible limitation was the differential procedure for participants completing the survey online and by pen and paper. Is it possible that the sense of anonymity was stronger for participants completing the measures online. Therefore, pen and paper participants might have suffered social desirability effects as they came face to face with the researcher in a way those completing the survey online did not. However, analyses indicated that none of the results were attributable to Impression Management effects. Moreover, to ensure participant anonymity, nationality of individual respondents was not recorded, meaning that it was not possible to assess possible differences between Swedish and English participants. Finally, the majority of the respondents were female, particularly among nurses where only one participant was male. It is therefore possible that some of the differences in 
attitudes among the occupational groups are attributable to gender differences in attitudes; however previous research generally supports the notion that both men and women have similar levels of RMA and AS, and that these attitudes are generally moderated by other factors (Jericho et al. 2015), and this was also supported in the current sample, where attributions of victim blame in either rape condition did not vary between the genders. Additionally, the current sample would be regarded as representative of the nursing community as around $90 \%$ of nurses in the UK are women (Williams, 2017).

Moreover, research on victim blame in rape cases most commonly involves a female victim and a male perpetrator. However, the small body of research involving male victims of rape suggests even higher levels of victim blame, particularly when the perpetrator is a woman (Bourke, 2007). It would therefore be of interest for future research to explore the role of perpetrator gender, RMA and AS in regards to victim and perpetrator blame in male rape. Furthermore, research suggests the closer the relationship between the victim and the perpetrator, the more blame is attributed to the victim (e.g. Bieneck \& Krahe, 2010). It would therefore be of interest to expand the acquaintance rape category and analyse the relationship between different victim-perpetrator relationships, victim blame, AS and RMA. In regards to diversity, the study and the background research focused on a majorly Caucasian population residing in Western Europe. Therefore, these results may not apply to different ethnicities and cultures. The focus of the study was heterosexual rape, which may render the results inapplicable to people of different sexualities. Finally, the background research and study has not specifically addressed the influence of disability.

\section{Conclusion}

In conclusion, research into blame attributions in sexual assault cases remains a crucial area of research, as attitudes held by the general public and medial professions have real life implications for rape victims. This study is the first of its kind to examine attitudes 


\section{ATTRIBUTIONS OF VICTIM BLAME}

among nurses and compare these with those of the general public. The analyses revealed that nurses, as compared to the general public, attributed more blame to the victim of acquaintance rape than the victim of stranger rape. Additionally, RMA and HS had a significant positive correlation with victim blame in the acquaintance rape condition, but not in the stranger rape condition. Furthermore, regression analyses revealed that victimperpetrator relationship, BS, HS and occupation contributed to the variance in attributed victim blame. Moreover, whether or not the participant was a nurse was the only significant contributor to blame attributions in the acquaintance rape scenario, whereas BS and HS were contributory variables in the stranger rape condition. These results suggest there are different processes involved in guilt attributions of victims of acquaintance rape as compared to victims of stranger rape, and that there are differences in how these are perceived among nurses as compared to the general public. By further examining attitudes within medical professions, it is possible that these services can be improved to better serve the needs of victims of sexual assault, as well as encouraging non-specialist nurses to spot possible victims seeking generalised care.

\section{Relevance to clinical practice}

The findings of this study are relevant to the clinical practice of nursing in a number of ways. Firstly, it highlights problems involved in rape victims accessing medical care following the assault; they are less likely than victims of other violent crimes to seek assistance, something that is particularly pronounced when the perpetrator is an acquaintance. This knowledge will be important for practicing nurses, as it suggests that these types of victims may need to be identified in novel ways (and thus encouraged to seek specialist care), for instance by accessing high-risk groups through general medical enquiries and not specialist sexual assault centres. Secondly, this research highlights attitudes surrounding rape and victim blame potentially held by practicing nurses, which could have an on impact the 


\section{ATTRIBUTIONS OF VICTIM BLAME}

care given to victims of sexual assault, particularly when the perpetrator is an acquaintance. As this paper also highlights previous research detailing the benefits of sexual assault training for nurses, it gives the recommendation that consent education and sexual assault awareness training should be routinely administered to all nurses, not just those working with sexual assault, as this will increase likelihood of identifying victims, as well and supporting them in the best possible way. Finally, by including participants from more than a single country, the study has the potential to be relevant to clinical practice in an international setting.

\section{References}

Abrams, D., Viki, T., Masser, B. \& Bohner, G. (2003). Perceptions of stranger and acquaintance rape: the role of benevolent and hostile sexism in victim blame and rape proclivity. Journal of Personality and Social Psychology, 84(1), 111-125.

Alexander, C. (1980). The responsible victim: nurses' perceptions of victims of rape. Journal of Health and Social Behaviour, 21(1), 22-23.

Bieneck, S. \& Krahé, B. (2011). Blaming the victim and exonerating the perpetrator in cases of rape and robbery: is there a double standard? Journal of Interpersonal Violence, 26(9), 1785-1797.

Bohner, G., Eyssel, F., Pina, A., Siebler, F. \& Viki, T. (2009). Rape Myth Acceptance: cognitive, affective and behavioural effects of beliefs that blame the victim and exonerate the perpetrator. In Horvath, M. \& Brown, J. (eds), Rape: Challenging Contemporary Thinking (pp. 46-73). Cullompton: Willan Publishing.

Bohner, G., Jarvis, C., Eysell, F. \& Siebler, F. (2005). The casual impact of Rape Myth Acceptance on men's rape proclivity: comparing sexually coercive and noncoercive men. European Journal of Social Psychology, 35(6), 819-828.

Bohner, G., Reinhard, M., Rutz, S., Sturm, S., Kerchbaum, B. \& Effler, D. (1988). Rape myths as neutralizing cognitions: evidence for a casual impact of anti-victim attitudes 
on men's self-reported likelihood of raping. European Journal of Social Psychology, 28(2), 257-268.

Bourke, J. (2007). Rape: a history from 1860 to the present. London: Virago Press.

Burt, M. (1980) Cultural myths and supports for rape. Journal of Personality and Social Psychology, 38(2), 217-230.

Campbell, R., Patterson, D. \& Bybee, D. (2012). Prosecution of adult sexual assault cases: A longitudinal analysis of the impact of a sexual assault nurse examiner program. Violence Against Women, 18(2), 223-244.

Castello, J. Coomer, C., Stillwell, J. \& Cate, K. (2006). The attribution of responsibility in acquaintance rape involving ecstasy. North American Journal of Psychology, 8(3) 411.

CDC. (2012). Sexual violence: Facts at a glance. Retrieved on 29/5 2017 from https://www.cdc.gov/violenceprevention/pdf/sv-datasheet-a.pdf.

Clark-Carter, D. (2003). Effect size: The missing piece in the Jigzaw. The Psychologist, 12(16) pp. 636-638.

Cowan, G. (2000). Beliefs about the causes of four types of rape. Sex Roles, 42(9), 807-823. Damrosch, S. (1985). How perceived carelessness and time of attach affect nursing students' attributions about rape victims. Psychological Reports, 56, 531-536.

EF. (2015) EF English Proficiency Index. (Online) (Accessed on 30/9 2015) http://www.ef.co.uk/epi/.

Feldhaus, K., Houry, D. \& Kaminsky, R. (2000). Lifetime sexual assault prevalence rates and reporting practices in an emergency department population. Annals of Emergency Medicine, 36(1), 23-27.

Frazier, P. \& Haney, B. (1996). Sexual assault cases in the legal system: police, prosecutor, and victim perspectives. Law and Human Behavior, 20(6), 607-628. 


\section{ATTRIBUTIONS OF VICTIM BLAME}

Frese, B., Moya, M. \& Medias, J. (2004). Social perception of rape: how Rape myth acceptance modulates the influence of situational factors. Journal of Interpersonal Violence, 19(2), 143.

Gerger, H., Kley, H. \& Bohner, G. (2007) 'The Acceptance of Modern Myths About Sexual Aggression scale: development and validation in German and English. Aggressive Behavior, 33(5), 422-440.

Gerger, H., Kley, H., Bohnber, G., Siebler, F. (2013) ‘Acceptance of Modern Myths About Sexual Aggression (AMMSA) scale. Measurement Instrument Database for the Social Science.

Glick, P. \& Fiske, S. (2011). Ambivalent Sexism revisited. Psychology of Women Quarterly, $35(3), 530-535$.

Glick, P. \& Fiske, S. (1996). The Ambivalent Sexism Inventory: differentiating Hostile and Benevolent Sexism. Journal of Personality and Social Psychology, 70(3). 491-512.

Grubb, A. \& Harrower, J. (2008). Understanding attribution of blame in cases of rape: an analysis of participant gender, type of rape and perceived similarity to the victim. Journal of Sexual Aggression, 15(1), 63-81.

Grubb, A. \& Turner, E. (2012). Attribution of blame in rape cases: a review of the impact of Rape Myth Acceptance, gender role conformity and substance use on victim blaming. Aggression and Violent Behavior, 17(5), 443-552.

Home Office. (2013). An overview of sexual offending in England and Wales. https://www.gov.uk/government/statistics/an-overview-of-sexual-offending-in$\underline{\text { england-and-wales }}$

Hockett, J., Smith, S., Klausing, C. \& Saucier, D. (2015). Rape myth consistency and gender differences in perceiving rape victims: A meta-analysis. Violence Against Women, 22(2), 139-167. 
Koss, M. (2000). Blame, shame, and community: justice responses to violence against women. American Psychologist, 55(11), 1332-1343.

Koss, M., Dinero, T., Seibel, C. \& Cox, S. (1988). Stranger and acquaintance rape: are there differences in the victim's experience? Psychology of Women Quarterly, 12, 1-24.

Krahé. B., Temkin, J., Bieneck, S. (2007). Schema-driven information processing in judgements about rape. Applied Cognitive Psychology, 21(5), 601-619.

Lehmann, R., Goodwill, A., Hanson, R. \& Dahle, K. (2015). Acquaintance rape: applying crime scene analysis to the prediction of sexual recidivism. Sex Abuse, 1-24.

Lisak, D. \& Miller, P. (2002). Repeat rape and multiple offending among undetected rapists. Violence and Victims, 17(1), 73-84.

Logan, T., Cole, J. \& Capillo, A. (2007). Differential characteristics of intimate partner, acquaintance, and stranger rape survivors examined by a Sexual Assault Nurse Examiner (SANE). Journal of Interpersonal Violence, 22(8), 1066-1076.

Masser, B., Lee, K. \& McKimmie, B. (2010). Bad woman, bad victim? Disentangling the effects of victim stereotypicality, gender stereotypicality, and Benevolent Sexism on acquaintance rape victim blame. Sex Roles, 62(7), 494-504.

McMillan, L. \& White, D. (2015). "Silly girls" and "nice lads": vilification and vindication in the perceptions of medico-legal practitioners in rape cases. Feminist Criminology, 10(3), 279-289.

Möller, A., Bäckström, T., Söndergaard, H. \& Helström, L. (2012). Patterns of injury and reported violence depending on relationship to assailant in Swedish sexual assault victims. Journal of Interpersonal Violence, 27(16), 3131-3148.

Paulhus, D. (1991). Measurement and control of response bias. In Robinson, J., Shaver, P. \& Wrightsman, L. (Eds.), Measures of personality and social psychological attitudes (pp. 17-59). San Diego: Academic Press. 
RAINN. (2016). Statistics. (Accessed 1/2 2017). https://www.rainn.org/statistics

Rape Crisis UK. (2015). Statistics. (Online) (Accessed on 29/9 2015)

http://rapecrisis.org.uk/statistics.php.

Schuller, R. \& Hastings, P. (2002). Complainant sexual history evidence: Its impact on mock jurors' decisions. Psychology of Women Quarterly, 26(3), 252-261.

Sleath, E. \& Woodhams, J. (2014). Expectations about victim and offender behaviour during stranger rape. Psychology, Crime \& Law, 20(8), 798-820.

Spohn, C. \& Holleran, D. (2001). Prosecuting sexual assault: a comparison of charging decisions in sexual assault cases involving strangers, acquaintances, and intimate partners. Justice Quarterly, 18(3), 651-688.

Strömwall, L., Alfredsson, H. \& Landström, S. (2013). Blame attributions and rape: effects of Belief in a Just World and relationship level. Legal and Criminological Psychology, $18(2), 254-261$.

Tjaden, P. \& Thoennes, N. (2006). Extent, nature, and consequences of rape victimization: findings from the national violence against women survey. National Institute of Justice. Washington.

Uji, M., Shono, M., Shikai, N. \& Kitamura, T. (2007). Rape myth scale: factor structure and relationship with gender egalitarianism among Japanese professionals. Psychiatry and Clinical Neurosciences, 61, 392-400.

Viki, T. \& Abrams, D. (2002). But she was unfaithful: benevolent sexism and reactions to rape victims who violate traditional gender role expectations. Sex Roles, 47(5), 289293.

Viki, T., Abrams, D. \& Masser, B. (2004) Evaluating stranger and acquaintance rape: The role of Benevolent Sexism in perpetrator blame and recommended sentence length. Law and Human Behavior, 28(3), 295-303. 
Wennstam, K. (2002). Flickan och skulden: en bok om samhällets syn på våldtäkt. Stockholm: Bonnier.

Williams, R. (2017, March 1st). Why are there so few male nurses? The Guardian. Retrieved from: https://www.theguardian.com/healthcare-network/2017/mar/01/why-so-fewmale-nurses. 
Table 1. Means and standard deviations for each key variable for nurses and the general public.

\begin{tabular}{lcccccc} 
& \multicolumn{3}{c}{ Nurses } & \multicolumn{3}{c}{ General Public } \\
Variable & Mean & SD & N & Mean & SD & N \\
Acquaintance Victim Blame & 2.12 & 1.16 & 19 & 1.80 & .979 & 25 \\
Stranger Victim Blame & 1.71 & .794 & 23 & 3.23 & .477 & 14 \\
BS & 1.52 & .788 & 42 & 1.56 & .532 & 36 \\
HS & 1.37 & .813 & 42 & 1.26 & .532 & 36 \\
ASI & 1.44 & .675 & 42 & 1.41 & .548 & 36 \\
AMMSA & .249 & .102 & 42 & .208 & .870 & 35
\end{tabular}


Table 2. Correlations for key variables among nurses and general public in the acquaintance and stranger rape conditions.

Nurses in the acquaintance rape condition

Variable

Victim Blame

AMMSA

BS

HS

Victim Blame

1

$.606^{* *}$

.439

$.538^{*}$

AMMSA

1

$.517 * *$

$.705^{* *}$

BS

1

$.436^{* *}$

HS

Nurses in the stranger rape condition

Variable

Victim Blame

AMMSA

BS

HS

Victim Blame

1

.101

.373

.255

AMMSA

1

$.517^{* *}$

$.705^{* *}$

BS

1

$.436^{* *}$

HS

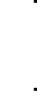

1

General public in the acquaintance rape condition

Variable

Victim Blame

AMMSA

BS

HS

Victim Blame

1

$.600^{* *}$

$.786^{* *}$

$.810^{* *}$

AMMSA

1

$.683^{* *}$

$.769 * *$

BS

1

$.676^{* *}$

HS

\section{$-$}

General public in the stranger rape condition

Variable

Victim Blame

AMMSA

BS

HS

Victim Blame

$-.125$

$-.427$

$-.033$

AMMSA

1

$.683^{* *}$

$.769^{* *}$

BS

-

1

$.676^{* *}$

HS

** Indicates that correlation is significant at $\mathrm{p}<0.01$ level. * Indicates that correlation is significant at $\mathrm{p}<.05$ level. 
Table 3. Regression analyses for the complete data set and for the two victimperpetrator relationship conditions, with the target variable attributed victim blame Complete data set

$\begin{array}{llllllll}\text { Variable } & \mathbf{B} & \mathbf{t} & \mathbf{D f} & \mathbf{p r} & \mathbf{R}^{2} & \text { AdjustedR }^{2} & \mathbf{p} \\ \text { Victim- } & .-554 & -5.59 & 1,70 & -.304 & .115 & .103 & .012^{*} \\ \text { perpetrator } & & & & & & & \\ \text { relationship } & & & & & & & \\ \text { BS } & .408 & 2.22 & 1,69 & .263 & .300 & .280 & .030^{*} \\ \text { HS } & .495 & 2.51 & 2,67 & .295 & .387 & .350 & .015^{*} \\ \text { Occupation } & .443 & 2.06 & 1,66 & .246 & .424 & .380 & .043^{*} \\ \text { AMMSA } & .015 & .090 & & .011 & & & .929\end{array}$

Acquaintance rape condition

$\begin{array}{llllllll}\text { Variable } & \mathbf{B} & \mathbf{t} & \mathbf{D f} & \mathbf{p r} & \mathbf{R}^{2} & \text { AdjustedR }^{2} & \mathbf{p} \\ \text { Occupation } & 1.54 & 3.93 & 1,23 & .634 & .491 & .402 & .001^{*} \\ \text { BS } & .185 & .745 & & .154 & & & .464 \\ \text { HS } & .252 & .700 & .144 & & .491 \\ \text { AMMSA } & .303 & .964 & & .197 & & .345\end{array}$

Stranger rape condition

$\begin{array}{llllllll}\text { Variable } & \mathbf{B} & \mathbf{t} & \mathbf{D f} & \mathbf{p r} & \mathbf{R}^{2} & \text { AdjustedR }^{2} & \mathbf{p} \\ \text { BS } & .825 & 3.50 & 2,40 & .494 & .470 & .458 & .001^{*} \\ \text { HS } & .466 & 2.32 & 2,40 & .345 & .545 & .510 & .025^{*} \\ \text { AMMSA } & .003 & .020 & & .003 & & & .985 \\ \text { Occupation } & -.285 & -1.37 & & -.213 & & & .180\end{array}$

* Variable contributes significantly to the variance in attributed victim blame. 